\title{
"From right to left": The role of right heart catheterization in the diagnosis and management of left heart diseases
}

\author{
Marta Kałużna-Oleksy ${ }^{A-F}$, Aleksander Araszkiewicz ${ }^{C-F}$, Jacek Migaj ${ }^{B, E, F}$, \\ Maciej Lesiak ${ }^{\mathrm{E}, \mathrm{F}}$, Ewa Straburzyńska-Migaj, ${ }^{\mathrm{A}, \mathrm{F}} \mathrm{F}$ \\ 15t Department of Cardiology, Poznan University of Medical Sciences, Poland \\ A - research concept and design; $\mathrm{B}$ - collection and/or assembly of data; $\mathrm{C}$ - data analysis and interpretation; \\ $D$ - writing the article; $E$ - critical revision of the article; $F$ - final approval of article
}

Address for correspondence

Marta Kałużna-Oleksy

E-mail:marta.kaluzna@wp.pl

Funding sources

none declared

Conflict of interest

none declared

Received on 0ctober 20, 2015

Revised on January 20,2016

Accepted on February 24, 2016

\begin{abstract}
Pulmonary hypertension (PH), second only to left heart diseases (LHD), is a frequent problem in clinical practice. At the same time, left heart diseases represent the most common cause of pulmonary hypertension, and the occurrence of $\mathrm{PH}$ in patients with chronic heart failure is usually associated with worse functional class, and prognosis. Right heart catheterization (RHC) is the "gold standard" in the diagnosis and differentiation of PH. It is also essential in the process of qualifying for a heart transplantation. Therefore, right heart catheterization should be performed in expert centers by experienced operators and according to a strict protocol to ensure the reliability and reproducibility of results. Recommendations for pulmonary hypertension due to left heart disease are based on the European Society of Cardiology (ESC) guidelines designed in cooperation with the European Respiratory Society (ERS) and the International Society for Heart and Lung Transplantation (ISHL). The new ESC guidelines for pulmonary hypertension published in 2015 have improved the diagnostic and therapeutic process in patients with left heart diseases.
\end{abstract}

Key words: pulmonary hypertension, right heart catheterization, left heart disease.

DOI

10.17219/acem/61908

Copyright

Copyright by Author(s)

This is an article distributed under the terms of the

Creative Commons Attribution Non-Commercial License

(http://creativecommons.org/licenses/by-nc-nd/4.0/) 


\section{Introduction}

Left heart diseases (LHD), including heart failure due to left ventricle (LV) systolic or diastolic dysfunction and valvular disorders, represent the most common causes of pulmonary hypertension $(\mathrm{PH}){ }^{1-3}$ Occurrence of $\mathrm{PH}$ in patients with chronic heart failure is usually associated with worsening of New York Heart Association (NYHA) functional class. Up to $60 \%$ patients with severe LV systolic dysfunction and up to $70 \%$ patients with isolated LV diastolic dysfunction develop $\mathrm{PH} .{ }^{4} \mathrm{PH}$ is usually associated with poor prognosis in patients with LHD. ${ }^{4,5}$ Right heart catheterization ( $\mathrm{RHC}$ ) is the "gold standard" in the diagnosis and differentiation of PH. RHC is also useful in determining the prognosis and eligibility for HTX.

The RHC is considered in patients with LHD prior to heart transplantation qualification. Acute vasoreactivity test is recommended in patients with $\mathrm{PH}$ and elevated PVR in HTX qualification process. ${ }^{6-8}$ The pressure and resistance measurements in those patients should be repeated every 6-12 months in patients without $\mathrm{PH}$ and every 3-6 months in patients with reversible $\mathrm{PH}^{6,7}$

Recommendations for $\mathrm{PH}$ resulting from left heart disease are based on the European Society of Cardiology (ESC) guidelines designed in cooperation with the European Respiratory Society (ERS) and the International Society for Heart and Lung Transplantation (ISHL). ${ }^{8}$ According to the recommendations the highest importance adhibit for the optimal treatment of underlying left heart disease in patients with $\mathrm{PH}$ is of the highest importance (I, B). ${ }^{8}$ Diagnosing $\mathrm{PH}$ in left heart diseases should include stepwise approach, combining clinical symptoms, specific echocardiographic features, ECG sings and other imaging techniques. Although increased left-sided filling pressure may be estimated by Doppler echocardiography, an invasive measurement of PWP or LV end-diastolic pressure may be required to confirm the diagnosis of $\mathrm{PH}$ resulting from $\mathrm{LHD}{ }^{8} \mathrm{RHC}$ may be considered in patients with suspected $\mathrm{PH}$ and left heart disease or lung disease to assist in the differential diagnosis and support treatment decisions (IIb, C). ${ }^{8} \mathrm{RHC}$ is recommended also in patients with $\mathrm{PH}$ resulting from left heart disease if organ transplantation is considered (I, C). ${ }^{8}$ It is recommended that RHC be performed in expert centers as it is technically demanding and may be associated with serious complications (I, B). ${ }^{8}$ The invasive assessment of $\mathrm{PH}$ should be performed in clinically stable patients with optimized volume status (I, C). ${ }^{8}$ There is no specific therapy for $\mathrm{PH}$ resulting from LHD. Sildenafil is a therapeutic option and new therapies that can show positive influence on $\mathrm{PH}$ resulting from LHD are currently under investigation. ${ }^{9}$ The ESC guidelines do not recommend the use of pulmonary arterial hypertension (PAH) specific drug therapy in PH-LHD (III, C). ${ }^{8}$ However, patients with $\mathrm{Cpc}-\mathrm{PH}$ should be enrolled in randomized controlled trials targeting $\mathrm{PH}$ specific drugs. ${ }^{8}$

\section{Pathophysiology of pulmonary hypertension}

Hemodynamic definition of $\mathrm{PH}$ resulting from LHD (PH-LDH) combines mean pulmonary arterial pressure $(\mathrm{PAP}) \geq 25 \mathrm{~mm} \mathrm{Hg}$, pulmonary wedge pressure (PWP) > $15 \mathrm{~mm} \mathrm{Hg}$, and normal or reduced cardiac output $(\mathrm{CO})$ at rest as assessed by right heart catheterization. ${ }^{8}$ The previous guidelines from 2009 underlined the role of the transpulmonary pressure gradient (TPG) (the difference between mean PAP and mean PWP), which was used to distinguish "passive" PH (TPG $\leq 12 \mathrm{~mm} \mathrm{Hg}$ ) from "reactive" PH (TPG > $12 \mathrm{~mm} \mathrm{Hg}) .{ }^{10}$ However, this definition and the associated terminology have been unsatisfactory; therefore, the diastolic pressure gradient (the difference between diastolic PAP and mean PWP; DPG) appears to best approach among the characteristics required to determine pulmonary vascular disease. ${ }^{11}$ The new guidelines of ESC recommend using a combination of DPG and PVR to define different types of PH$\mathrm{LDH}$, i.e. isolated post-capillary pulmonary hypertension (Ipc-PH) and combined post-capillary and pre-capillary pulmonary hypertension (Cpc-PH) (Table 1, Fig. 1). ${ }^{8}$

The pathophysiologic chain leading to PAP elevation includes LV heart failure causing chronic pulmonary congestion (elevated pulmonary vein pressure) and secondary changes of pulmonary vessels, which lead to increased pulmonary vascular resistance (PVR). The consequence of these changes is right ventricular heart failure.

Changes in pulmonary circulation are similar in every type of $\mathrm{PH}$ - elevated blood pressure in pulmonary circulation (congestion) causes dilation and thickening of pulmonary veins, pulmonary capillary dilation, interstitial edema, alveolar hemorrhage, and lymphatic vessel and lymph node enlargement. ${ }^{10}$ Distal pulmonary arteries may develop medial hypertrophy and intimal fibrosis. ${ }^{10}$ However, in PH resulting from LHD these changes are secondary to PAP elevation that is primarily caused by heart failure. Patients with PH resulting from LHD demonstrate increased pressure in the left atrium. ${ }^{12}$

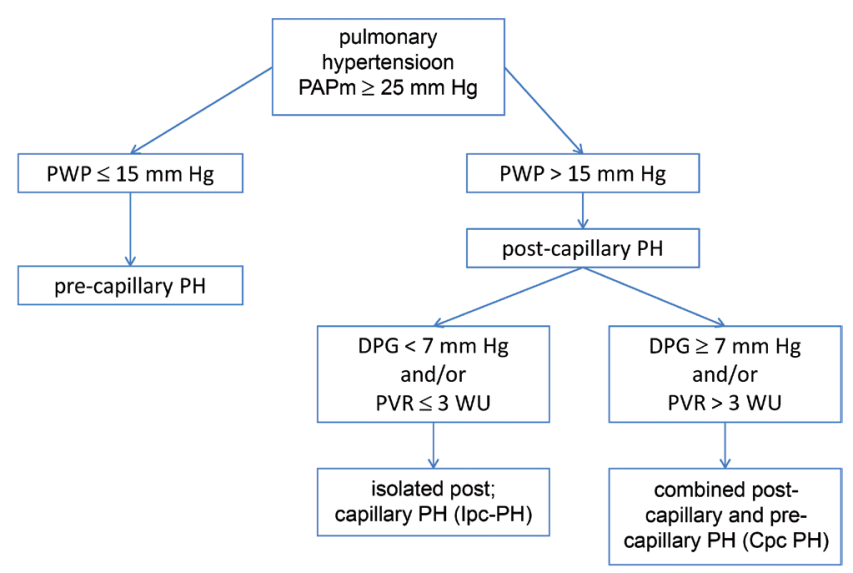

Fig. 1. Definition of pulmonary hypertension 
Table 1. Hemodynamic definitions of pulmonary hypertension' [8]

\begin{tabular}{|c|c|c|}
\hline Definition & Characteristics $^{1}$ & Clinical group(s) \\
\hline Pulmonary hypertension (PH) & mean PAP $\geq 25 \mathrm{~mm} \mathrm{Hg}$ & all \\
\hline Pre-capillary PH & $\begin{array}{l}\text { mean } P A P \geq 25 \mathrm{~mm} \mathrm{Hg} \\
P W P \leq 15 \mathrm{~mm} \mathrm{Hg}\end{array}$ & $\begin{array}{l}\text { 1. pulmonary arterial hypertension } \\
\text { 3. } \mathrm{PH} \text { due to lung diseases } \\
\text { 4. chronic thromboembolic PH } \\
\text { 5. PH with unclear and/or multifactorial mechanisms }\end{array}$ \\
\hline Post-capillary PH & $\begin{array}{l}\text { mean PAP } \geq 25 \mathrm{~mm} \mathrm{Hg} \\
\quad P W P>15 \mathrm{~mm} \mathrm{Hg}\end{array}$ & $\begin{array}{l}\text { 2. } \mathrm{PH} \text { due to left heart disease } \\
\text { 5. } \mathrm{PH} \text { with unclear and/or multifactorial mechanisms }\end{array}$ \\
\hline Isolated post-capillary PH (Ipc-PH) & \multicolumn{2}{|c|}{$\mathrm{DPG}<7 \mathrm{~mm} \mathrm{Hg}$ and/or $\mathrm{PVR} \leq 3 \mathrm{WU}^{2}$} \\
\hline Combined post-capillary and pre-capillary PH (Cpc-PH) & \multicolumn{2}{|c|}{$\mathrm{DPG} \geq 7 \mathrm{~mm} \mathrm{Hg}$ and/or $\mathrm{PVR}>3 \mathrm{WU}^{2}$} \\
\hline
\end{tabular}

${ }^{1}$ All values measured at rest, ${ }^{2}$ Wood units are preferred to dynes.s. $\mathrm{cm}^{-5}$; PAP - pulmonary arterial pressure, PH - pulmonary hypertension, PWP - pulmonary wedge pressure, DPG - diastolic pressure gradient (diastolic PAP - mean PWP), PVR - pulmonary vascular resistance, WU - Wood units.

\section{History of right heart catheterization}

The concept of right heart catheterization was created in 1929 by Forssmann, who advanced a urethral catheter into his own heart by accessing an "elbow vein" (probably antecubital) to deliver drugs directly into the heart. ${ }^{13}$

Methods of application of the right heart catheter developed further. It was used to measure right heart pressure and cardiac output, which improved the understanding of cardiopulmonary hemodynamics and gas exchange. ${ }^{14,15}$ Understanding these mechanisms was a significant step towards the assessment of a patient's clinical state. The biggest challenge was the ability to obtain a continuous recording of human central hemodynamic parameters. This was achieved by Swan et al. in 1970. They added a balloon to the catheter tip of a standard pulmonary artery catheter (PAC), allowing for flow-directed movement and positioning. ${ }^{16}$ Balloon-tipped PAC not only facilitated bedside placement via floatation of the catheter tip downstream. It has also provided an opportunity to measure the pressure in the right atrium and the pulmonary arteries continuously, and the pulmonary capillary wedge pressure intermittently, via inflation and deflation of the balloon. Adding a thermistor to the tip of a catheter allowed a direct measurement of cardiac output with the thermodilution technique (using temperature as the indicator), which was possible because of the discoveries made by Ganz et al. ${ }^{17}$ Since that time, the PAC has been called a "Swan-Ganz" catheter. This catheter provides a continuous central hemodynamic monitoring, being an important and useful tool in intensive care units. Several prospective studies were performed to evaluate the outcomes of PAC use in a variety of acute medical and surgical conditions ${ }^{18,19}$, including exacerbation of chronic heart failure. ${ }^{20}$

PAC plays an invaluable role in the history of medicine. It is one of the most useful tools that improved the understanding and management of various diseases, particularly acute heart failure, exacerbation of chronic heart failure and shock. An intense assessment of its general application in non-acute and non-shock exacerbated heart fail- ure has now been provided by the ESCAPE trial, a landmark investigation that showed an overall neutral impact of PAC-guided therapy over therapy guided by clinical evaluation and judgment alone. ${ }^{21}$ The current guidelines recommend the use of PAC for the management of refractory heart failure and selected conditions (e.g. pulmonary hypertension, transplant evaluation).

\section{Diagnostics of $\mathrm{PH}$ resulting from LHD}

The symptoms that occur in patients with $\mathrm{PH}$ resulting from LHD are unspecific. Patients often develop dyspnea, worsening of exercise tolerance, chest pain and sings of congestive right or left heart failure. Occasionally, patients may present with palpitations or hemoptysis. The first step in diagnostics is a physical examination and clinical assessment. Accessory tests include basic laboratory parameters, electrocardiography, chest X-ray, echocardiography, and occasionally cardiopulmonary exercise testing. Echocardiography allows for the estimation of pressure in the pulmonary circulation and may suggest the cause of $\mathrm{PH} .{ }^{22}$ The right heart catheterization is reserved for special situations. The RHC is considered in patients with LHD prior to heart transplantation qualification; in patients in whom diagnosis of $\mathrm{PH}$ would alter management (e.g. with valvular heart disease); in patients suspected of exercise-induced $\mathrm{PH}$; before therapy employment in patients with suspected pulmonary arterial hypertension (PAH); and in selected cases during follow-up. ${ }^{12}$

\section{Technical aspects of right heart catheterization}

$\mathrm{RHC}$ is required to objectively confirm $\mathrm{PH}$. This procedure allows us to assess the severity of the disease, and to test the vasoreactivity of the pulmonary circulation.

Although the current guidelines recommend $\mathrm{RHC}^{8}$ for diagnostic evaluation and monitoring of treatment 
in patients with $\mathrm{PH}$, specific recommendations how to perform this procedure are rare. New guidelines for hemodynamic and angiographic evaluation of pulmonary circulation have already been published ${ }^{6-8}$, which try to systematize indications and give some technical tips how to perform the RHC.

$\mathrm{RHC}$ is an invasive diagnostic procedure and should be performed in expert centers. Severe complications, possibly fatal, are not frequent, but the health care center has to be prepared to treat them. The overall number of severe adverse events is assessed $1.1 \%$ with the overall procedure-related mortality of $0.055 \% .{ }^{23}$ The complications of RHC can be classified into three groups: complications associated with the access, with the catheter position in pulmonary circulation and with the vasoreactivity test. The most common complications are: hematomas (5.3\%), intramural hematomas caused by catheter placement (28-61\%), benign arrhythmias (> 20\%). ${ }^{24}$

RHC may be technically difficult and demanding, and it has to be conducted according to a strict protocol to ensure reproducibility of results. The pressure transducer should be set up prior to measurement. The initial settings of the pressure transducer should be standardized, because they influence the hemodynamic results, especially RAP and PWP. ${ }^{25}$ The recommendation for zeroing the pressure transducer suggests zeroing at the midthoracic line in a supine position, halfway between the anterior portion of sternum and the bed surface. ${ }^{26}$ This represents the level of the left atrium. ${ }^{26}$

Based on the current guidelines dated on $2015^{8}$ the following variables have to be recorded during $\mathrm{RHC}$ :

- Pulmonary arterial pressure = PAP (systolic, diastolic, mean)

- Right atrial pressure $=$ RAP

- Pulmonary wedge pressure = PWP, which should be recorded as a mean of 3 measurements at end-expiration ${ }^{26}$ - Right ventricular pressure $=$ RVP $^{8}$

The high superior vena cava, inferior vena cava, pulmonary artery (PA), and systemic arterial blood oxygen saturations should also be determined ${ }^{8}$, along with the heart rate and systemic blood pressure. Cardiac output (CO) must be measured thrice, preferably by thermodilution or by Fick's method, if oxygen consumption is assessed. ${ }^{8}$ Fick's method is mandatory in the presence of a systemic-to-pulmonary shunt. ${ }^{8}$ The preferred method of measuring $\mathrm{CO}$ is thermodilution, which provides reliable measurements even in patients with very low $\mathrm{CO}$ and/or severe tricuspid regurgitation. ${ }^{27}$ However, the gold standard for $\mathrm{CO}$ measurement is direct Fick's method, which requires direct measurement of the oxygen uptake, and is not widely available. Instead of this, many health care centers use indirect Fick's method, which uses estimated values for oxygen uptake derived from tables. ${ }^{26}$ It is necessary to remember that using the thermodilution method with Swan-Ganz catheter (placed in the pulmonary artery), the de facto pulmonary flow is measured..$^{6,7}$ If there
Table 2. The hemodynamic parameters in pulmonary circulation - based on

\begin{tabular}{|lc|}
\hline Parameters & Normal range \\
\hline Central venous pressure (CVP) & $3-8 \mathrm{~mm} \mathrm{Hg}$ \\
Right atrium pressure (RAP) mean & $0-8 \mathrm{~mm} \mathrm{Hg}$ \\
Right ventricle pressure (RVP) systolic & $15-30 \mathrm{~mm} \mathrm{Hg}$ \\
Pulmonary artery pressure (PAP) & \\
systolic & $15-30 \mathrm{~mm} \mathrm{Hg}$ \\
mean & $8-20 \mathrm{~mm} \mathrm{Hg}$ \\
diastolic & $3-12 \mathrm{~mm} \mathrm{Hg}$ \\
Pulmonary wedge pressure (PCWP) & $4-15 \mathrm{~mm} \mathrm{Hg}$ \\
Left atrium pressure (LAP) mean & $2-12 \mathrm{~mm} \mathrm{Hg}$ \\
Left ventricle end-diastolic pressure & $5-12 \mathrm{~mm} \mathrm{Hg}$ \\
Cardiac output (CO) & $4-8 \mathrm{~L} / \mathrm{min}$ \\
Cardiac index (Cl) & $2.5-4.2 \mathrm{~L} / \mathrm{min} \times \mathrm{m}^{2}$ \\
Pulmonary vascular resistance (PVR) & $<2.5 \mathrm{WU}$ \\
Total pulmonary resistance (TPR) & $<3.5 \mathrm{WU}$ \\
Pulmonary vascular resistance index (PVRI) & $<3.0 \mathrm{WU}$ \\
Systemic vascular resistance (SVR) & $10-20 \mathrm{WU}$ \\
Oxygen saturation in pulmonary trunk & $70-80 \%$ \\
\hline
\end{tabular}

WU $=$ Wood units.

is no shunt between systemic and pulmonary circulation, pulmonary flow is identical with systemic flow. ${ }^{6,7}$

Those measurements are required to calculate pulmonary vascular resistance (PVR). Adequate recording of PWP is required for the differential diagnosis of $\mathrm{PH}$ resulting from LHD. ${ }^{8}$ A PWP > $15 \mathrm{~mm} \mathrm{Hg}$ excludes the diagnosis of pre-capillary PAH. ${ }^{8}$ Heart failure with a preserved ejection fraction (HFpEF) and a diastolic dysfunction is one of the most challenging differential diagnoses of PAH. ${ }^{28}$ In such patients, PWP may be mildly elevated or at the upper limit of the reference range at rest. ${ }^{10}$ Interpretation of PWP should be taken only in the clinical context. In many patients with LHD, PWP may be reduced to $<15 \mathrm{~mm} \mathrm{Hg}$ with diuretics. ${ }^{29,} 30$ In those situations, the effect of an acute volume challenge on left heart filling pressure has been considered. ${ }^{31}$ Limited data suggests that a fluid bolus of $500 \mathrm{~mL}$ appears to be safe and may discriminate patients with PAH from those with LV diastolic dysfunction. ${ }^{32}$

Normal ranges of hemodynamic parameters in pulmonary circulation are listed in Table 2.

\section{Right heart catheterization in heart transplantation consideration process}

Although the role, significance and settings of pharmacological testing remain unclear in PH resulting from LHD, it is recommended in heart transplantation candidates to identify patients at a higher risk of acute post- 
Table 3. Recommendation for diagnostic RHC in heart transplant candidates ${ }^{36}$

\begin{tabular}{|c|c|c|}
\hline Statement & Class of recommendation & Level of evidence \\
\hline $\begin{array}{l}\text { Right heart catheterization (RHC) should be annually on all candidates in preparation for listing for } \\
\text { cardiac transplantation until transplantation }\end{array}$ & 1 & C \\
\hline $\begin{array}{l}\text { RHC should be performed at 3- to 6-month in listed patients, especially in the presence of } \\
\text { reversible pulmonary hypertension or worsening of heart failure symptoms }\end{array}$ & 1 & C \\
\hline $\begin{array}{l}\text { A vasodilator challenge should be when the pulmonary artery systolic pressure is } \geq 50 \mathrm{~mm} \mathrm{Hg} \\
\text { and either the transpulmonary gradient (TPG) is } \geq 15 \text { or the pulmonary vascular resistance (PVR) } \\
\text { is }>3 \text { Wood units while maintaining a systolic arterial blood pressure }>85 \mathrm{~mm} \mathrm{Hg}\end{array}$ & । & C \\
\hline $\begin{array}{l}\text { When an acute vasodilator challenge is unsuccessful hospitalization with continuous } \\
\text { hemodynamic monitoring should be performed, as often the PVR will decline after } 24 \text { to } 48 \text { h of } \\
\text { treatment consisting of diuretics, inotropes and vasoactive agents such as inhaled nitric oxide }\end{array}$ & I & C \\
\hline $\begin{array}{l}\text { If medical therapy fails to achieve hemodynamics and, if the left ventricle cannot be effectively } \\
\text { unloaded with mechanical adjuncts, including an intra-aortic balloon pump (IABP) and/or left } \\
\text { ventricular assist device (LVAD), it is reasonable to conclude that the pulmonary hypertension is } \\
\text { irreversible }\end{array}$ & $\mathrm{Ilb}$ & C \\
\hline
\end{tabular}

operative RV failure. ${ }^{33}$ In heart transplantation candidates, a persistent increase in PVR > 2.5 Wood units and/ or TPG > $15 \mathrm{~mm} \mathrm{Hg}$ are associated with up to a 3-fold increase in risk of RV failure and early post-transplant mortality. ${ }^{34}$ This risk may be reduced, when PVR can be lowered pharmacologically (e.g. with i.v. nitroprusside) - vasoreactivity testing. ${ }^{35}$

According to ISHLT guidelines concerning heart transplantation qualification, $\mathrm{RHC}$ is one of the most important examinations. Indications for diagnostic right heart catheterization in heart transplant candidates are listed in Table $3 .^{36}$

\section{Vasoreactivity testing}

According to ISHLT, a vasoreactivity test should be performed when PVR is $>3$ Wood units, TPG $>15 \mathrm{~mm} \mathrm{Hg}$, Spap $>50 \mathrm{~mm} \mathrm{Hg}$ and systolic systemic arterial pressure is not lower than $85 \mathrm{~mm} \mathrm{Hg} .{ }^{37}$ However, it seems that such a test should be performed at earlier stages of vascular pulmonary disease (PVD), when the PVR is $>2.5$ Wood units and TPG> $12 \mathrm{~mm} \mathrm{Hg} .{ }^{38}$ If during a vasoreactivity test the previously increased PVR is reduced to less than 2.5 Wood units, HTX becomes possible, if not accompanied by a drop in systemic pressure $<85 \mathrm{~mm} \mathrm{Hg.,7}$ If the reduction of PVR is accompanied by systemic hypotonia, the patient remains at risk for early postoperative right ventricular failure and increased perioperative mortality. ${ }^{39}$

A vasoreactivity test should be carried out under conditions of optimal alignment of the circulatory system with systolic blood pressure of at least $85 \mathrm{~mm} \mathrm{Hg.6,7}$ The following substances are presently recommended: sodium nitroprusside (NPS), nitric oxide (NO), milrinone, sildenafil, prostaglandin E1 IV or a synthetic analog of prostacyclin (iloprost) inhalation, ${ }^{6,7}$ while according to the new ESC guidelines inhaled nitic oxide (at 10-20 parts per million (ppm)) is the standard of care for vasoreactivity testing (I, C). ${ }^{8}$ Intravenous epoprostenol (I, C), intravenous adenosine (IIa, C) or inhaled iloprost (IIb, C) can be used as alternatives. ${ }^{8}$ Although a variety of drugs are used in different centers, the current scientific evidence suggests a relationship with transplantation outcomes only for the tests with sodium nitroprusside (Fig. 2). ${ }^{40} \mathrm{~A}$ positive response to vasoreactivity testing is defined as a reduction of mean PAP $\geq 10 \mathrm{~mm} \mathrm{Hg}$ to reach an absolute value of mean PAP $\leq 40 \mathrm{~mm} \mathrm{Hg}$ with an increased or unchanged cardiac output (I, C). ${ }^{8}$ In HTX qualification process $\mathrm{PH}$ is recognized as reversible, if in the vasoreactivity test with one of above-mentioned substances, reduction of PVR is $<2.5-3$ Wood units, TPG $<12 \mathrm{~mm} \mathrm{Hg}$ without downfall of systemic blood pressure. ${ }^{6,7}$

RHC determines contraindications to heart transplantation. The RHC parameters assessed in the heart transplantation candidates are e.g. PVR and TPG (Table 4). ${ }^{36}$

Table 4. Important hemodynamic parameters to assess potential transplant candidates ${ }^{36}$

Pulmonary artery hypertension and elevated PVR should be considered as a relative contraindication to cardiac transplantation when the PVR is $>5$ Wood units or the PVR is $>6$ or the TPG exceeds 16 to $20 \mathrm{~mm} \mathrm{Hg}$

If the PAS exceeds $60 \mathrm{~mm} \mathrm{Hg}$ in conjunction with any 1 of the preceding 3 variables, the risk of right heart failure and early death is increased

If the PVR can be reduced to $<2.5$ with a vasodilator but the systolic blood pressure falls $<85 \mathrm{~mm} \mathrm{Hg}$, the patient remains at high risk of right heart failure and mortality after cardiac transplantation

Calculations: transpulmonary gradient (TPG [mPAP - PCWP]); pulmonary vascular resistance (PVR [TPG/CO Wood units]); pulmonary vascular resistance index (PVRI [TPG/CI]) 


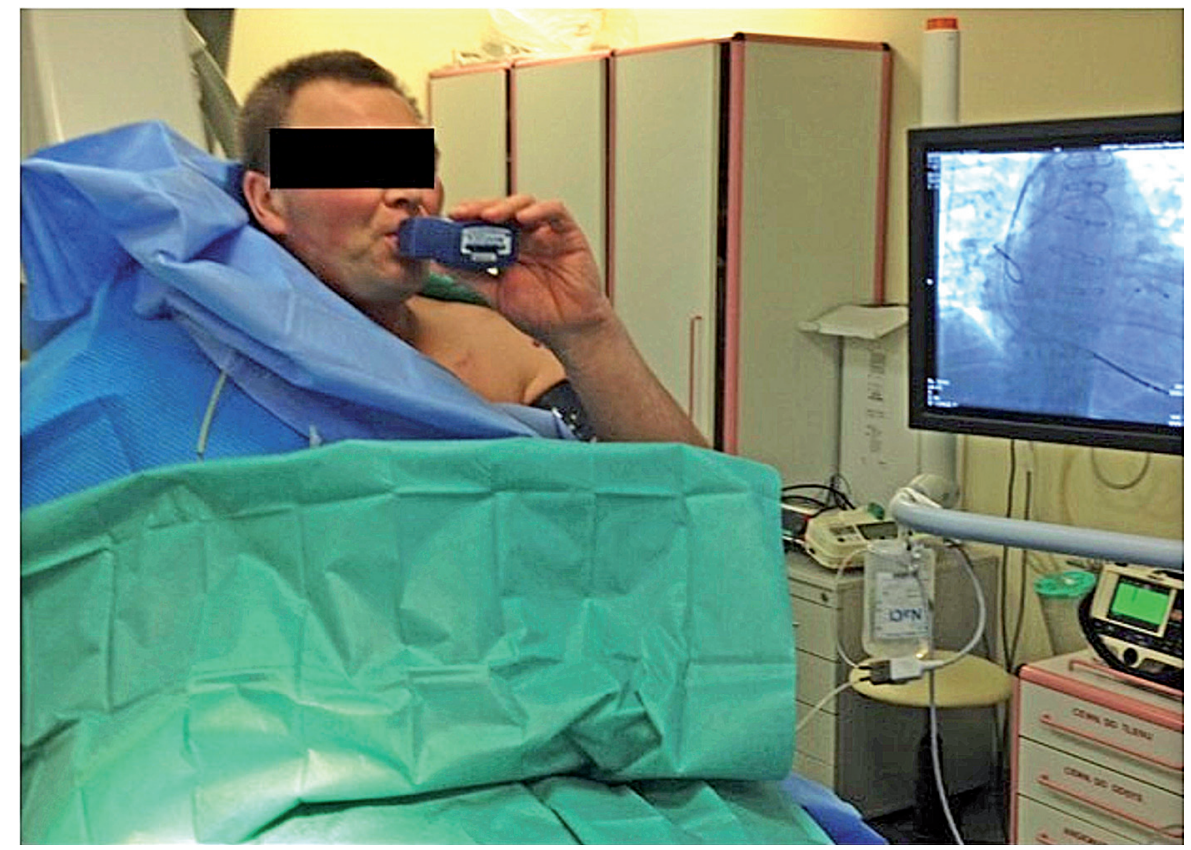

Fig. 2. Vasoreactivity test in patients with dilated cardiomyopathy. Patient inhaled $5 \mu \mathrm{g}$ of iloprost with use of I-Neb ultrasonic nebulizer

\section{Summary}

Pulmonary hypertension, secondary to left heart disease, is a frequent problem in the clinical practice. With the clinical state of HF patients worsening, the incidence of $\mathrm{PH}$ increases. Right heart catheterization as the "gold standard" in diagnosis and differentiation of pulmonary hypertension is a very important part of heart transplantation qualification process. There are efficient and feasible diagnostic methods available, and the number of sites able to diagnose $\mathrm{PH}$ is constantly increasing There still remains, however, the problem of a lack of targeted causal treatment. Specialists have limited therapeutic possibilities which relieve the symptoms in patients with $\mathrm{PH}$, however the outcomes still remain unsatisfactory.

\section{References}

1. Guglin $\mathrm{M}$, Khan H. Pulmonary hypertension in heart failure. J Card Fail. 2010;16:461-474.

2. Guazzi M, Arena R. Pulmonary hypertension with left-sided heart disease. Nat Rev Cardiol. 2010;7:648-659.

3. Hoeper MM, Barbera JA, Channick RN, et al. Diagnosis, assessment and treatment of non-pulmonary arterial hypertension pulmonary hypertension. J Am Coll Cardiol. 2009;54:S85-S96.

4. Ghio S, Gavazzi A, Campana C, et al. Independent and additive prognostic value of right ventricular systolic function and pulmonary artery pressure in patients with chronic heart failure. J Am Coll Cardiol. 2001;37:183-188.

5. Abramson SV, Burke JF, Kelly JJ Jr, et al. Pulmonary hypertension predicts mortality and morbidity in patients with dilated cardiomyopathy. Ann Intern Med. 1992;116:888-895.

6. Kurzyna M, Araszkiewicz A, Błaszczak P, et al. Standardy hemodynamicznej $\mathrm{i}$ angiograficznej oceny krążenia płucnego. Kardiol Pol. 2014;72:45-64.

7. Kurzyna M, Araszkiewicz A, Błaszczak P, et al. Summary of recommendations for the haemodynamic and angiographic assessment of the Polish Cardiac Society's Working Group on Pulmonary Circulation and Association of Cardiovascular Interventions. Kardiol Pol. 2015;73(1):63-68.
8. Galié N, Humbert M, Vachiery JL, et al. 2015 ESC/ERS Guidelines for the diagnosis and treatment of pulmonary hypertension: The Joint Task Force for the Diagnosis and Treatment of Pulmonary Hypertension of the European Society of Cardiology (ESC) and the European Respiratory Society (ERS), Endorsed by: Association for European Paediatric and Congenital Cardiology (AEPC), International Society for Heart and Lung Transplantation (ISHLT) [Epub ahead of print]. Eur Heart J. 2015. doi:10.1093/eurheartj/ehv317.

9. Urbanowicz T, Straburzyńska-Migaj E, Katyńska I, et al. Sustained improvement of clinical status and pulmonary hypertension in patients with severe heart failure treated with sildenafil. Ann Transplant. 2014;19:325-330.

10. Galié N, Hoeper MM, Humbert M, et al. Guidelines for the diagnosis and treatment of pulmonary hypertension: The Task Force for the Diagnosis and Treatment of Pulmonary Hypertension of the European Society of Cardilogy (ESC) and the European Respiratory Society (ERS), endorsed by the International Society of Heart and Lung Transplantation (ISHLT). Eur Heart J. 2009;30:2493-2537.

11. Vachiery JL, Adir Y, Barbera JA, et al. Pulmonary hypertension due to left heart disease. J Am Coll Cardiol. 2013;62:D100-D108.

12. Haddad F, Kudelko K, Mercier O, Vrtovec B, Zamanian RT, de Jesus Perez V. Pulmonary hypertension associated with left heart disease: characteristics, emerging concepts, and treatment strategies. Prog Cardiovasc Dis. 2011;54:154-167.

13. Forssmann W. The catheterization of the right side of the heart. Klin Wochenschr. 1929;45:2085-2087.

14. Cournand A. Catheterization of the right auricle in man. Proc Soc Exp Biol Med. 1941;46:462-466.

15. Cournand A, Bloomfield RA. Recording of right pressure in man. Proc Soc Exp Biol Med. 1944;55:34-36.

16. Swan HJ, Ganz W, Forrester J, Marcus H, Diamond G, Chonette D. Catheterization of the heart in man with use of a flow-directed balloon-tipped catheter. N Engl J Med. 1970;283(9):447-451.

17. Ganz W, Donoso R, Marcus HS, Forrester JS, Swan HJ. A new technique for measurment of cardiac output by thermodilution in man. Am J Cardiol. 1971;27:392-396.

18. Connors AF, Speroff T, Dawson NV, et al. The effectiveness of right heart catheterization in the initial care of critically ill patients. SUPPORT investigators. JAMA. 1996;276:889-897.

19. Harvey S, Harrison DA, Singer M, et al. Assessment of the clinical effectiveness of pulmonary artery catheters in management of patients in intensive care (PAC-Man): A randomized controlled trial. Lancet. 2005;366:472-477. 
20. The ESCAPE Investigators. Evaluation study of congestive heart failure and pulmonary artery catheterization effectiveness: The ESCAPE trial. JAMA. 2005;294:1625-1633.

21. Kahwash R, Leier CV, Miller L. Role of the pulmonary artery catheter in diagnosis and management of heart failure. Cardiol Clin. 2011;29:281-288.

22. Thenappan T, Shah SJ, Gomberg-Maitland M, et al. Clinical characteristics of pulmonary hypertension in patients with heart failure and preserved ejection fraction. Circ Heart Fail. 2011;4:257-265.

23. Hoeper MM, Lee SH, Voswinckel R, et al. Complications of right heart catheterization procedure in patients with pulmonary hypertension in experienced centers. J Am Coll Cardiol. 2006;48:2546-2552.

24. American Society of Anesthesiologists Task Force on Pulmonary Artery Catheterization. Practice guidelines for pulmonary artery catheterization: An updated report by the American Society of Anesthesiology Task Force on Pulmonary Artery Catheterization. Anesthesiology. 2003;99:988-1014.

25. Kovacs G, Avian A, Olschewski A, Olschewski H. Zero reference level for right heart catheterization. Eur Respir J. 2013;42:1586-1594.

26. Hoeper MM, Bogaard HJ, Condliffe R, et al. Definitions and diagnosis of pulmonary hypertension. J Am Coll Cardiol. 2013;62:D42-50.

27. Hoeper MM, Maier R, Tongers J, et al. Determination of cardiac output by the Fick method, thermodilution, and acetylene rebreathing in pulmonary hypertension. Am J Respir Crit Care Med. 1999; 160:535-541.

28. Paulus WJ, Tschöpe C, Sanderson JE, et al. How to diagnose diastolic heart failure: A consensus statement on the diagnosis of heart failure with normal left ventricular ejection fraction by the Heart Failure and Echocardiography Associations of the European Society of Cardiology. Eur Heart J. 2007;28:2539-2550.

29. Frost $A E$, Farber HW, Barst RJ, Miller DP, Elliott CG, McGoon MD. Demographics and outcomes of patients diagnosed with pulmonary hypertension with pulmonary capillary wedge pressures 16 to $18 \mathrm{~mm}$ Hg: Insights from the REVEAL Registry. Chest. 2013;143:185-195.

30. Abraham WT, Adamson PB, Bourge RC, et al. Wireless pulmonary artery haemodynamic monitoring in chronic heart failure: $A$ randomised controlled trial. Lancet. 2011;377:658-666.

31. Fujimoto $\mathrm{N}$, Borlaug $\mathrm{BA}$, Lewis $\mathrm{GD}$, et al. Hemodynamic responses to rapid saline loading: The impact of age, sex, and heart failure. Circulation. 2013;127:55-62.
32. Robbins IM, Hemnes AR, Pugh ME, et al. High prevalence of occult pulmonary venous hypertension revealed by fluid challenge in pulmonary hypertension. Circ Heart Fail. 2014;7:116-122.

33. Costanzo MR, Augustine S, Bourge R, et al. Selection and treatment of candidates for heart transplantation. A statement for health professionals from the Committee on Heart Failure and Cardiac Transplantation of the Council on Clinical Cardiology, American Heart Association. Circulation. 1995;92:3593-3612.

34. Chang PP, Longenecker JC, Wang NY, et al. Mild vs severe pulmonary hypertension before heart transplantation: Different effects on posttransplantation pulmonary hypertension and mortality. J Heart Lung Transplant. 2005;24:998-1007.

35. Costard-Jackle A, Fowler MB. Influence of preoperative pulmonary artery pressure on mortality after heart transplantation: Testing of potential reversibility of pulmonary hypertension with nitroprusside is useful in defining a high risk group. J Am Coll Cardiol. 1992;19:48-54.

36. Mehra MR, Kobashigawa J, Starling R, et al. Listing criteria for heart transplantation: International Society of Heart and Lung Transplantation Guidelines for the care of cardiac transplant candidates - 2006. J Heart Lung Transplant. 2006;25:1024-1042.

37. Halpern SD, Taichmann DB. Misclassification of pulmonary hypertension due to reliance on pulmonary capillary wedge pressure rather than left ventricular end-diastolic pressure. Chest. 2009;136:37-43.

38. Swierad M, Zakliczynski M, Maruszewski M, et al. Reversibility of pulmonary hypertension assessment as an expected standard of diagnosis and prognosis on cardiology ward in Poland. Kardiol Pol. 2009;67:106-109.

39. Francis GS, Greenberg BH, Hsu DT, et al. ACCF/AHA/ACP/HFSA/ISHLT 2010 clinical competence statement on management of patients with advanced heart failure and cardiac transplant: $A$ report of the ACCF/AHA/ACP Task Force on Clinical Competence and Training. J Am Coll Cardiol. 2010;56:424-453.

40. Zakliczynski M, Zebik T, Maruszewski M, Swierad M, Zembala M. Usefulness of pulmonary hypertension reversibility test with sodium nitroprusside in stratification of early death risk after orthotopic heart transplantation. Transplant Proc. 2005;37:1346-1348. 